\title{
CHLORMEQUAT SELECTIVE ELECTRODES: CONSTRUCTION, EVALUATION AND APPLICATION AT FIA SYSTEMS
}

\author{
M. GORETI F. SALES, NUNO F.M.C. LINO and PAULA C.B. PAI' GA
}

\section{ABSTRACT}

A flow injection analysis (FIA) system having a chlormequat selective electrode is proposed. Several electrodes with poly(vinyl chloride) based membranes were constructed for this purpose. Comparative character- ization suggested the use of membrane with chlormequat tetraphenylborate and dibutylphthalate. On a single-line FIA set-up, operating with $1 \times 10^{-2} \mathrm{~mol} \mathrm{~L}^{-1}$ ionic strength and $6.3 \mathrm{pH}$, calibration curves presented slopes of $53.6 \pm 0.4 \mathrm{mV}$ decade ${ }^{-1}$ within $5.0 \times 10^{-6}$ and $1.0 \times 10^{-3} \mathrm{~mol} \mathrm{~L}^{-1}$, and squared correlation coeffi- cients $>0.9953$. The detection limit was $2.2 \times 10^{-6} \mathrm{~mol} \mathrm{~L}^{-1}$ and the repeatability equal to $\pm 0.68 \mathrm{mV}(0.7 \%)$. A dual-channel FIA manifold was therefore constructed, enabling automatic attainment of previous ionic strength and $\mathrm{pH}$ conditions and thus eliminating sample preparation steps. Slopes of $45.5 \pm 0.2 \mathrm{mV}$ dec- ade ${ }^{-1}$ along a concentration range of $8.0 \times 10^{-6}$ to $1.0 \times 10^{-3}$ $\mathrm{mol} \mathrm{L}^{-1}$ with a repeatability $\pm 0.4 \mathrm{mV}(0.69 \%)$ were obtained. Analyses of real samples were performed, and recovery gave results ranging from 96.6 to $101.1 \%$.

Keywords: Chlormequat; Growth regulator; Pesticides; Potentiometry; lon-selective electrode; FIA

\section{INTRODUCTION}

Plant growth retardants are applied in agronomic and horticultural crops to reduce unwanted longitudinal shoot growth without lowering plant productivity. Most growth retardants act by inhibiting gibberellin biosynthesis. To date, four different types of such inhibitors are known, among which are the onium compounds such as chlormequat chloride (CMQ-Cl), the 2-chlorethyltrimethylammonium [1].

Chlormequat (CMQ) is extensively used in agriculture for its growth regulating properties as it also presents the ability to control ozone damage to wheat by protecting it against yield reduction [2]. Overall, the attainment of better crops is connected to the mode and concentration of its application. This feature is directly associated with the amount of active compound among the commercial preparations and for which they must be accurately controlled. Furthermore, this widespread 
promote contamination of waters, fruits, cereals and vegetables and thus its quantifica-tion becomes fundamental.

With respect to residues in food and water, the quantification of $\mathrm{CMQ}-\mathrm{Cl}$ is exten- sively described in the literature and some of the methods have also been applied to the analysis of commercial preparations. Due to the overall complexity of the relevant sample matrices, as well as the low concentrations expected in contaminated samples, almost all methods require a detection system capable of producing both quantitative and qualitative information. For this reason mass spectrometry is nearly the only detec- tion system proposed in the literature, and may be associated with liquid chromatogra- phy [3-13], thin layer chromatography [14] and electrophoresis systems $[15,16]$. Independently of the separation approach, the use of mass spectrometry is connected to high capital investment, which makes it unsuitable for routine applications. Conductimetric detection coupled to ion chromatography $[17,18]$ and indirect UV detection coupled to electrophoresis $[15,19]$ are alternative strategies suggested in the literature. In some cases they may be difficult to implement if the equipment is not available in the analytical laboratory. Chemical transformation of the analyte with sodium phenylsulfide [20] or potassium pentafluorothiophenolate [21] has also been exploited in order to enable a gas chromatographic detection. The latter has been considered not sufficiently specific for CMQ and this may be misleading to an analyst using it or adapting it to other procedures [22].

Other proposals in the literature concern electroanalytical systems. Since CMQ is not an electroactive compound, the glassy carbon electrode of a voltammetric detector has been modified with a cation-exchanger membrane [23]. This approach has advantages concerning the environment but it has not been applied to natural samples. Also a potentiometric-based method has been described in the literature and this has advantages regarding emission of effluents of low toxicity [24]. It is not specific for the analyte. It involves a titration with tetraphenylborate and other compounds within samples may react with this chemical and promote analytical errors.

An alternative to previous methods would be a potentiometric determination by means of a CMQ selective electrode. The required equipment is of low cost and is common in analytical laboratories. The system allows a selective detection of the analyte with emission of low toxicity aqueous effluents. In order to obtain adequate working characteristic for performing direct readings of $\mathrm{CMQ}$ in various sample matrices, several selective membranes will be proposed and discussed.

The widespread use of growth regulators suggests the need for a routine control of this compound and especially for industries with a daily production of phytopharma- ceuticals. In this sense, a simple automatic system such as the flow injection analysis (FIA) technique will be implemented and selective detectors will be constructed with a tubular configuration which is a suitable shape for this flow method. 
The potential differences between indicating and reference electrodes were measured by means of a Crison $\mathrm{mpH} 2002$ decimillivoltammeter ( $\pm 0.1 \mathrm{mV}$ sensitivity) coupled to a Metrohm E 586 recorder. The reference electrode was an Orion (90-02-00) 


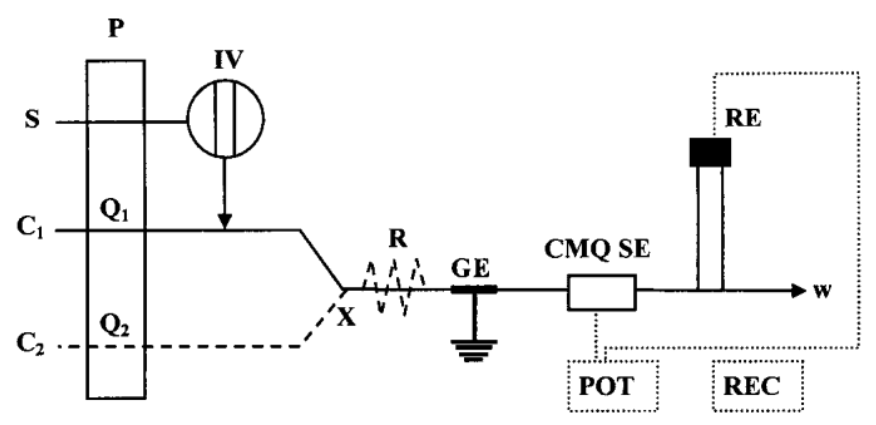

FIGURE 1 FIA set-up for evaluation of working characteristics of the potentiometric detector (channel $C_{1}$ ) and analyzing real samples (channels $C_{1}$ and $C_{2}$ ). P: peristaltic pump; S: sample; $C_{1}$ : IS or buffer solution, both with $1 \times 10^{-7} \mathrm{~mol} \mathrm{~L}^{-1}$ of $\mathrm{CMQ}$, or water regarding the analysis of samples; $\mathrm{C}_{2}$ : buffer solution with 2

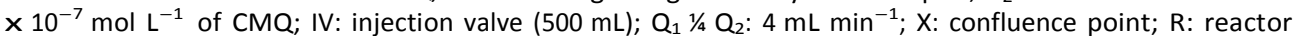
length of $20 \mathrm{~cm}$; GE: ground electrode; CMQ SE: CMQ selective electrode; RE: reference electrode; w: waste; POT: decimillivoltammeter; and REC: recorder.

double junction electrode. The selective electrode, with no internal reference solution presented a tubular configuration and was constructed as described elsewhere [25]. When necessary, pH values were monitored by means of a GAH 110 combined glass electrode connected to a decimillivoltammeter.

The FIA system (Figure 1) comprised a Gilson Minipuls 2 peristaltic pump, fitted with PVC tubing $(0.80,1.60$ and/or $2.00 \mathrm{~mm}$ i.d.) and a four-way Rheodyne 5020 injection valve holding loops of 100, 200, 500 or $1000 \mathrm{~mL}$. All components were gathered by PTFE tubing (Omnifit, Teflon, $0.8 \mathrm{~mm}$ i.d.), Gilson end-fittings and connectors. The support devices for tubular and reference electrodes, as well as the confluence pointaccessory were constructed in Perspex ${ }^{\oplus}$ as reported elsewhere [26].

\section{Reagents and Solutions}

All chemicals were of analytical grade and deionised water (conductivity $<0.1 \mathrm{mS}$ $\mathrm{cm}^{-1}$ ) was employed. Several reagents were used throughout, namely $\mathrm{CMQ}-\mathrm{Cl}$ (Fluka), barium chloride (Merck), o-phosphoric acid (85\%, Merck), and calcium hydroxide $(96 \%$, Riedel-deHae" $n)$. For the selective membrane preparation, tetraphenyl- borate (TPB) sodium (Aldrich), bis(2-ethylhexyl)sebacate (bEHS, Fluka), onitrophenyl octyl ether (oNFOE, Fluka), dibutylphthalate (DBP), poly(vinyl chloride) of high mol-

ecular weight (PVC, Fluka) and tetrahydrofuran (THF, Riedel-deHae“ n) were used. Evaluation of the effects of both $\mathrm{pH}$ and interfering ionic species at the potentiometric response required sodium hydroxide (Merck), hydrochloric acid (37\%, Merck), sodium chloride (Merck), potassium chloride (Merck), magnesium chloride (Riedel-deHae" n), calcium chloride (Merck), ammonium chloride (Merck), hydroxylammonium chloride (Riedel-deHae" n) and diquat (Riedel-deHae“ n).

Concentrated standard stock solutions were prepared by rigorous weighing of the corresponding solids and subsequent dilution with ionic strength (IS) adjuster, buffer solution or water. Less concentrated solutions were obtained by careful dilution of the stock solution with the appropriate diluent.

The IS adjuster was a $3.3 \times 10^{-3} \mathrm{~mol} \mathrm{~L}^{-1} \mathrm{BaCl}_{2}$ solution, with an IS equal to 1 $\times 10^{-2} \mathrm{~mol} \mathrm{~L}^{-1}$. The simultaneous $\mathrm{pH}$ and ionic strength adjustment was obtained with a $\mathrm{H}_{3} \mathrm{PO}_{4} / \mathrm{Ca}(\mathrm{OH})_{2}$ buffer solution having a pH of 6.3 and an IS of $1 \times 10^{-2} \mathrm{~mol} \mathrm{~L}^{-1}$. 
This buffer was prepared by mixing $125.0 \mathrm{~mL}$ of a $1 \times 10^{-2} \mathrm{~mol} \mathrm{~L}^{-1} \mathrm{H}_{3} \mathrm{PO}_{4}$ solution with $75.0 \mathrm{~mL}$ of a $1 \times 10^{-2} \mathrm{~mol} \mathrm{~L}^{-1} \mathrm{Ca}(\mathrm{OH})_{2}$ solution, subsequently diluting to a final volume of $500.0 \mathrm{~mL}$. In the double channel set-up (channel $C_{3}$ in Figure 1), this buffer solution was prepared with double concentration values but maintaining the same $\mathrm{pH}$. Apart from other chemicals, the carrier solution (either in channel $\mathrm{C}_{1}$ or $\mathrm{C}_{2}$ in

Figure 1) included an amount of $\mathrm{CMQ}-\mathrm{Cl}$ equal to $1 \times 10^{-7}$ or $2 \times 10^{-7} \mathrm{~mol} \mathrm{~L}^{-1}$, respectively. This small amount of analyte was included to improve baseline stabilization and preserve the selective membrane thus avoiding a continuous leaching of sensor towards waste. Standard solutions were prepared in carrier solutions, having no CMQ-Cl.

For the study of the effect of $\mathrm{pH}$ upon the potentiometric response, a solution of $5.0 \times 10^{-4} \mathrm{~mol} \mathrm{~L}^{-1} \mathrm{CMQ}$, prepared in IS adjuster, was selected. The interference of other chemicals was studied for $5.0 \times 10^{-5}, 1.0 \times 10^{-4}$ and $5.0 \times 10^{-4} \mathrm{~mol} \mathrm{~L}^{-1}$ concentrations of $\mathrm{CMQ}-\mathrm{Cl}$ and sodium chloride, potassium chloride, magnesium chloride, calcium chloride, ammonium chloride, hydroxylammonium chloride or diquat. All these solutions were made in $3.3 \times 10^{-3} \mathrm{~mol} \mathrm{~L}^{-1}$ of $\mathrm{BaCl}_{2}$.

\section{Construction of CMQ Selective Electrodes}

The ionic sensor (CMQ-TPB) was prepared by precipitation, mixing $25.0 \mathrm{~mL}$ of a $1.0 \times 10^{-2} \mathrm{~mol} \mathrm{~L}^{-1} \mathrm{CMQ}-\mathrm{Cl}$ solution and $50.0 \mathrm{~mL}$ of a $1.0 \times 10^{-2} \mathrm{~mol} \mathrm{~L}^{-1}$ sodium TPB solution. The resulting solution was allowed to stand for $24 \mathrm{~h}$, protected from light and in an ice-bath. The precipitate was removed from the solution by filtration. After thorough washing with water, the filtered precipitate was kept in a dark flask inside a dessicator to prevent changes caused by light and humidity.

Sensor solutions were obtained by dissolving about $0.0200 \mathrm{~g}$ of the previous ionic sensor in $1.0000 \mathrm{~g}$ of oNFOE, bEHS or DBP. The corresponding membrane solutions were prepared by mixing $0.20 \mathrm{~mL}$ of the previous solution with $0.09 \mathrm{~g}$ of $\mathrm{PVC}$, formerly dissolved in about $2 \mathrm{~mL}$ of THF. The overall composition of the previous membranes, designated types A, B and C, respectively, as indicated in Table I.

The selective electrodes were prepared by applying membrane solutions to a tubular conductive support of graphite and epoxy resin [25]. The membrane was allowed to dry for $24 \mathrm{~h}$ and then put into $1 \times 10^{-3} \mathrm{~mol} \mathrm{~L}^{-1} \mathrm{CMQ}-\mathrm{Cl}$ solution prepared in water. The electrodes were stored in these conditions when not in use.

\section{Procedures}

The general working characteristics of the potentiometric detectors were assessed in a single-channel FIA manifold (channel $C_{1}$ in Figure 1 ) using as carrier IS adjuster or

TABLE I Overall membrane composition (\%, $\mathrm{w} / \mathrm{w}$ ) of the CMQ selective electrodes

\begin{tabular}{lccc}
\hline Components & $A$ & $B$ & $C$ \\
\hline CMQ-TPB & 1.3 & 1.3 & 1.3 \\
oNFOE & 67.5 & - & - \\
BEHS & - & 66.6 & - \\
DBP & - & - & 67.2 \\
PVC & 31.2 & 32.1 & 31.5
\end{tabular}



buffer solution to which had been added a small amount of CMQ-Cl. The injection volume was $500 \mathrm{~mL}$ and the flow rate $4 \mathrm{~mL} \mathrm{~min}^{-1}\left(Q_{1}\right)$. The results reported are mean values of at least four calibrations. Repeatability was represented by the standard deviation of at least 15 injections of a standard CMQ solution and the response time was estimated in terms of sampling rate.

The influence of $\mathrm{pH}$ on the potentiometric response was evaluated for a $5.0 \times 10^{-4} \mathrm{~mol} \mathrm{~L}^{-1} \mathrm{CMQ}-\mathrm{Cl}$ solution at different $\mathrm{pH}$ values. A small adaptation of the single-channel manifold consisting of a closed loop circuit with continuous circulation of $200 \mathrm{~mL}$ of the previous standard solution was required. The $\mathrm{pH}$ was altered by addition of small amounts of a saturated $\mathrm{NaOH}$ solution or concentrated $\mathrm{HCl}$, and was monitored by an additional potentiometric cell consisting of a combined glass electrode connected to a second decimillivoltammeter. The solutions selected for changing the $\mathrm{pH}$ values were highly concentrated in order to prevent significant alterations of the concentration of $\mathrm{CMQ}$ in solution. Additionally, and with the exception of $\mathrm{Na}^{\mathrm{b}}$, they also avoided the introduction of other chemical species into the system (other than those already present: $\mathrm{Ba}^{2 \mathbf{b}}, \mathrm{Cl}^{-}$and $\mathrm{CMQ}$ ). $\mathrm{NaOH}$ was selected instead of

$\mathrm{Ba}(\mathrm{OH})_{2}$ because of the low solubility of the latter. For each $\mathrm{pH}$ measurement an amount of $500 \mathrm{~mL}$ was inserted into a $4 \mathrm{~mL} \mathrm{~min}{ }^{-1}$ carrier stream of IS adjuster. Ranges of $\mathrm{pH}$ defined as satisfactory allowed a $\pm 5 \mathrm{mV}$ variation in the analytical signal.

The selectivity was evaluated by the separated solutions method [27], and performed by separately injecting $500 \mathrm{~mL}$ of a $\mathrm{CMQ}-\mathrm{Cl}$ solution andother possible interfering com-pound solutions into a single-channel FIA manifold with a carrier stream of

$3.3 \times 10^{-3} \mathrm{~mol} \mathrm{~L}^{-1} \mathrm{BaCl}_{2}$, flowing through the detector at $4 \mathrm{~mL} \mathrm{~min}^{-1}$.

Prior to the analysis of natural samples, total flow-rate and injection volume were optimized in a multivariate way by recording the operating characteristics of the detec-tor for a $1 \times 10^{-6}$ to $1 \times 10^{-3} \mathrm{~mol} \mathrm{~L}^{-1}$ concentration range, and under $\mathrm{pH}$ and IS adjustment conditions. For this, a double-channel FIA manifold was set-up with 100, 200, 500 or $1000 \mathrm{~mL}$ injection volumes, and 3, 4, 5, 6, 7 or $8 \mathrm{~mL} \mathrm{~min}^{-1}$ overall flow-rates. For the analyses of samples, the potentiometric response was recorded in the double- channel FIA manifold, operating simultaneously with channels $C_{1}$ and $C_{2}$ (Figure 1). Water and buffer solution with a small amount of CMQ-Cl respectively were selected as carriers. This last solution had IS and CMQ concentration values double to those of the single-channel carrier as it would be diluted by half at the confluence point

(X, Figure 1).

\section{Sample Preparation}

The only phytopharmaceutical preparation of $\mathrm{CMQ}$, commercialized in Portugal as Cycocel $^{\circledR}$ was labeled as containing $400 \mathrm{~g} \mathrm{~L}^{-1}$ of $\mathrm{CMQ}$, expressed in the hydrochloride form. To perform recovery trials, and considering the extremely high concentration of CMQ in the sample, a stock solution of sample was first prepared by measuring an exact amount of $39.5 \mathrm{~mL}$ and diluting it with water to a final volume of 100.00 $\mathrm{mL}$. A $3000 \mathrm{~mL}$ volume of this solution was diluted with water to a final volume of

$50.00 \mathrm{~mL}$; the expected concentration was $7.7 \times 10^{-5} \mathrm{~mol} \mathrm{~L}^{-1} \mathrm{CMQ}$. Recovery trials were then performed with a similarly prepared solution of $3000 \mathrm{~mL}$ of a $1.00 \times 10^{-2} \mathrm{~mol} \mathrm{~L}^{-1} \mathrm{CMQ}$ standard solution before completing the final volume up 
to $50.00 \mathrm{~mL}$; expected concentration was $7.0 \times 10^{-4} \mathrm{~mol} \mathrm{~L}^{-1} \mathrm{CMQ}$.

Since it was not possible to find contaminated waters in Portuguese territory, a river water sample was collected and doped with the $\mathrm{Cycocel}^{\circledR}$ leading to an expected 
contamination $160 \mathrm{mg} \mathrm{L^{-1 }}$. This was considered as the stock sample solution. Further dilutions for the potentiometric analysis and recovery trials were performed similarly to those previously mentioned with respect to the phytopharmaceutical preparation.

Results regarding analysis of samples correspond to mean values of eight determina- tions.

\section{RESULTS AND DISCUSSION}

To effect the construction of CMQ selective electrodes with proper working characteristics, three polymeric membranes were prepared, presenting basically the same overall composition but with different plasticizing solvents (oNFOE, bEHS and DBP). Apart from different chemical structures they presented very different polarity characteristics, with dielectric constants equal to $23.6,6.4$, and 4.6 respectively [28]. This property was very important for the ion exchange process within the selective membranes.

The behavior of each $\mathrm{CMQ}$ selective electrode was assessed so that the best detector could be selected for the analysis of natural samples.

\section{Working Characteristics of CMQ Selective Electrodes}

The working characteristics of the several CMQ selective electrodes, established in a single-channel FIA manifold (Figure 1), were evaluated for both IS and simultaneous $\mathrm{pH}$ and IS adjustment conditions. The latter required a $\mathrm{pH}$ of 6.3 , in agreement with the following $\mathrm{pH}$ study. A $500 \mathrm{~mL}$ injection volume and a $4 \mathrm{~mL} \mathrm{~min}{ }^{-1}$ flow-rate were selected with the purpose of establishing experimental conditions close to those in the stationary state. The three types of electrodes presented a very low limit for the linear range, equal to $5 \times 10^{-6} \mathrm{~mol} \mathrm{~L}^{-1}$, a similar and low response time, and a quite different repeatability, varying within 0.8 and $1.7 \%$ (Table II).

Regarding the IS adjustment trials, results indicated a slightly higher sensitivity for type $C$ detectors (Table II), suggesting that a low polarity solvent could improve the behavior of the selective electrodes. However, the variation within these results could not probably be attributed only to the physical properties of the solvent, especially considering the small difference between the dielectric constants of the DBP and bEHS. Supporting this possibility, Amstrong et al. reported a decrease of the oNFOE dielectric constant to \pm 12 when incorporated in $33 \%$ of PVC [29]. This

TABLE II Working characteristics of CMQ selective electrodes with the single-channel FIA manifold

\begin{tabular}{|c|c|c|c|c|c|c|}
\hline \multirow{2}{*}{$\begin{array}{l}\text { Working } \\
\text { characteristics }\end{array}$} & \multicolumn{3}{|c|}{ IS $\left(1 \times 10^{-2} \mathrm{~mol} \mathrm{~L}^{-1}\right)$} & \multicolumn{3}{|c|}{$p H(6.3)$ and IS $\left(1 \times 10^{-2} \mathrm{~mol} \mathrm{~L}^{-1}\right) \mathrm{A}$} \\
\hline & & B & $\mathrm{C}$ & $A$ & B & $\mathrm{C}$ \\
\hline $\operatorname{LLLR}^{(\mathrm{a})}\left(\mathrm{mol} \mathrm{L}^{-1}\right)$ & $5.0 \times 10^{-6}$ & $5.0 \times 10^{-6}$ & $5.0 \times 10^{-6}$ & $5.0 \times 10^{-6}$ & $5.0 \times 10^{-6}$ & $5.0 \times 10^{-6}$ \\
\hline $\mathrm{DL}^{(\mathrm{b})}\left(\mathrm{mol} \mathrm{L}^{-1}\right)$ & $2.5 \times 10^{-6}$ & $3.9 \times 10^{-6}$ & $2.9 \times 10^{-6}$ & $2.8 \times 10^{-6}$ & $3.6 \times 10^{-6}$ & $2.2 \times 10^{-6}$ \\
\hline Slope (mV decade $\left.{ }^{-1}\right)$ & $46.9 \pm 1.1$ & $42.5 \pm 0.3$ & $49.7 \pm 0.6$ & $39.5 \pm 1.0$ & $51.1 \pm 2.6$ & $53.6 \pm 0.4$ \\
\hline $\begin{array}{l}\text { Repeatability }{ }^{(c)} \\
( \pm m V)\end{array}$ & \multicolumn{6}{|c|}{ $\pm 0.59(0.9 \%) \pm 0.51(0.8 \%) \pm 1.11(1.2 \%) \pm 1.02(1.7 \%) \pm 1.06(1.4 \%) \pm 0.68(0.7 \%)$} \\
\hline R squared & $>0.9995$ & $>0.9936$ & $>0.9989$ & $>0.9906$ & $>0.9909$ & $>0.9953$ \\
\hline Sampling rate $\left(\mathrm{h}^{-1}\right)$ & 80 & 84 & 75 & 85 & 80 & 72 \\
\hline
\end{tabular}


$\mathrm{pH}$ working range $\mathrm{e}^{(\mathrm{d})} \quad 2.3-9.8$

4-11

2.3-11.8

${ }^{(a)}$ Lower limit of linear range; ${ }^{(b)}$ detection limit; ${ }^{(c)}$ at $1.0 \times 10^{-4} \mathrm{~mol} \mathrm{~L}^{-1}$; (d) at $5.0 \times 10^{-4} \mathrm{~mol} \mathrm{~L}^{-1}$. 
phenomenon was explained as the restriction of the free rotation of the mediator sol- vent molecules while in a polymeric matrix.

Studies with solutions of adjusted $\mathrm{pH}$ and IS confirmed the better operating charac- teristics of type $C$ detector (Table II), mainly because of an increase of $8 \%$ in sensitivity of the potentiometric response when compared with previous results. Under these conditions, type B working characteristics also improved, particularly in the slope increase of 20\%. While slopes of type B and C electrodes improved, those of type $A$ indicated a decrease of $16 \%$ in sensitivity. In fact these results demonstrate that low polarity solvents would be more appropriate for preparing CMQ selective electro- des although the chemical structure of DBP must have influenced the potentiometric response leading to the best electrodes.

Operational $\mathrm{pH}$ ranges were unusually wide for the three types of electrodes (Table II). Only at very low $\mathrm{pH}$ values did the analytical signals show a tendency to a small increase, which would be linked to $\mathrm{H}^{\mathrm{b}}$ interference at the potentiometric response. Increasing $\mathrm{pH}$ to a value of 10 gave rise to constant potentials at all electrodes, which may be linked to the extent of ionization of $\mathrm{CMQ}$ remaining constant even at very high $\mathrm{pHs}$. As the $\mathrm{pH}$ increased after 10-12 units, the potentials showed a slight tendency to decrease.

Interference of several ionic species on CMQ determinations was evaluated in terms of potentiometric selectivity coefficients. The three membranes showed a similar behavior (Table III), with a relative order of interference of $\mathrm{Mg}^{2 \mathrm{p}}<\mathrm{Ca}^{2 \mathrm{p}}:::$ diquat $\ll \mathrm{Na}^{\mathrm{p}}::: \mathrm{K}^{\mathrm{b}} \ll \mathrm{NH}_{4}{ }^{\mathrm{p}}, \mathrm{HONH}_{3}{ }^{\mathrm{b}}$. Basically, interference of all cations concerned was considered negligible. Very low coefficients were recorded for $\mathrm{Mg}^{2 \mathrm{~b}}$ and $\mathrm{Ca}^{2 \mathrm{p}}$, both doubly charged ions. Considering type $\mathrm{B}$ and $\mathrm{C}$ detectors, potassium showed a slightly stronger effect than sodium, most probably due to its ionic size, closer to

that of an ammonium ion. Both ammonium and hydroxylammonium showed the strongest interfering effect, a consequence of the similarity of the ionized group to the $\mathrm{CMQ}$ structure. Injection of pure solutions of ammonium ions always gave rise to analytical signals much lower than those produced by the main ion. Because it is included in the same pesticide group as $\mathrm{CMQ}$, diquat interference was evaluated and found to be negligible.

In the single-channel FIA manifold, the preparation of any natural samples would require the use of buffer solution instead of water. If this requirement were only con- nected to a previous dilution, it would be practically indifferent using either of the two as solvent. However, in a routine application, other samples may be the object of other

TABLE III Potentiometric selectivity coefficients of CMQ selective electrodes

\begin{tabular}{lccc}
\hline Interference $^{(\mathrm{a})}$ & \multicolumn{3}{c}{ IS $\left(1 \times 10^{-2} \mathrm{~mol} \mathrm{~L}^{-1}\right)$} \\
\cline { 2 - 4 } & $\mathrm{A}$ & $\mathrm{B}$ & $\mathrm{C}$ \\
\hline Potassium & $-2.350 \pm 0.256$ & $-1.877 \pm 0.008$ & $-1.699 \pm 0.105$ \\
Sodium & $-2.329 \pm 0.143$ & $-2.116 \pm 0.012$ & $-2.170 \pm 0.113$ \\
Magnesium & $-4.409 \pm 0.160$ & $-4.134 \pm 0.027$ & $-4.329 \pm 0.248$ \\
Calcium & $-4.282 \pm 0.097$ & $-3.947 \pm 0.145$ & $-4.137 \pm 0.115$ \\
Ammonium & $-1.604 \pm 0.101$ & $-1.907 \pm 0.037$ & $-1.995 \pm 0.259$ \\
Hydroxylammonium & $-0.758 \pm 0.256$ & $-1.583 \pm 0.024$ & $-2.118 \pm 0.126$ \\
Diquat & $-3.177 \pm 0.080$ & $-3.936 \pm 0.008$ & $-3.182 \pm 0.186$ \\
\hline
\end{tabular}


(a) at $5.0 \times 10^{-4} \mathrm{~mol} \mathrm{~L}^{-1}$. 
treatments that could promote an undesired high consumption of reagents, leading to resources dissipation as well as to higher amount of effluents. For this reason a double- channel manifold that enabled automatic adjustment of required conditions inside the manifold, thus permitting sample preparation with only water, was established.

\section{Optimization of a Double-channel FIA Manifold}

Prior to analysis of natural samples, suitable experimental conditions should be selected. Thus, the effect of parameters such as flow-rate and injection volume was object of study. After the confluence point of the two channels (X, Figure 1 ), a reactor was included in order to guarantee adequate mixing of the solutions. A length of $20 \mathrm{~cm}$ was found appropriate for this purpose and kept constant during the several trials.

For each injection volume selected, the increase in flow-rate led to both a slope increase and a lower limit of linear range decrease. These variations were not very per-ceptible when the flow-rate was changed from 7 to $8 \mathrm{~mL} \mathrm{~min}^{-1}$. The latter was however selected, since it promoted an increase in sampling rate that ranged from $5 \%$ (in case of 100 and $200 \mathrm{~mL}$ injection volumes) to $24 \%$ (in case of $500 \mathrm{~mL}$ loop) therefore reduced the estimated time for analysis.

Though peak heights increased as injection volume was augmented, the recorded sen- sitivity did not change significantly. The highest slope values were attained with the injection of 500 and $1000 \mathrm{~mL}$ sample volumes. Regarding sampling-rate, the former volume enabled the analysis of a larger number of samples per time unit, which decreased to about $42 \%$ when $1000 \mathrm{~mL}$ was used.

The overall optimization process indicated that satisfactory operating characteristics would be obtained by the injection of $500 \mathrm{~mL}$ into a stream crossing the detector at $8 \mathrm{~mL} \mathrm{~min}^{-1}$. Because the sample plug was here divided by two, the operating characteristics of the type $C$ detectors altered and again characterized giving the mean values indicated in Table IV. Under these conditions, the proposed method has a detection limit of

$0.8 \mathrm{mg} \mathrm{mL}^{-1}$ and is able to quantify at least $1.3 \mathrm{mg} \mathrm{mL}^{-1}$. When compared with similar conditions at the single-channel manifold, the slope decreased in about $15 \%$ but the sampling rate increased to more than double about $108 \%$.

\section{Analysis of Samples}

Before analysis, the potentiometric system was calibrated under the optimum conditions. After dilution with water the mean potentiometric results for the technical concentrate (Cycocel ${ }^{\oplus}$ ) were near the labeled amount, at about $-4.8 \%$ (Table V). They

TABLE IV Working characteristics of CMQ selective electrodes with the double-channel FIA manifold

\begin{tabular}{lc}
\hline Working characteristics & $p H(6.3)$ and IS $\left(1 \times 10^{-2} \mathrm{~mol} \mathrm{~L}^{-1}\right)$ \\
& $\mathrm{C}$ \\
\hline $\operatorname{LLLR}^{\text {(a) }}\left(\mathrm{mol} \mathrm{L}^{-1}\right)$ & $8.0 \times 10^{-6}$ \\
$\mathrm{DL}^{(\mathrm{b})}\left(\mathrm{mol} \mathrm{L}^{-1}\right)$ & $5.2 \times 10^{-6}$ \\
Slope $\left(\mathrm{mV} \mathrm{decade}^{-1}\right)$ & $45.5 \pm 0.2$ \\
Repeatability & $( \pm \mathrm{mV})$ \\
\end{tabular}


${ }^{\text {(a) }}$ Lower limit of linear range; ${ }^{(b)}$ detection limit; ${ }^{(c)}$ at $1.0 \times 10^{-4} \mathrm{~mol} \mathrm{~L}^{-1}$. 
also presented low standard deviations with a relative value of $2.2 \%$, indicating a good precision. A typical fiagram of this analysis is depicted in Figure 2 .

River water was collected and doped not with pure standard but with Cycocel . The estimated amount, expressed in the hydrochloride form, was $160 \mathrm{mg} \mathrm{L}^{-1}$ of $\mathrm{CMQ}$. Mean potentiometric results were near this value (b5.1\%), and the precision of the method was confirmed by a low standard deviation (Table V).

Because it was not possible to perform the reference procedure, based on ionchromatography and conductimetric detection [30], the accuracy of the currently proposed method was estimated only by recovery experiments (Figure 2). Recovery trials presented mean values of 97 and $101 \%$ with low standard deviations (Table V), demonstrating the accuracy of the proposed method and again confirming good preci-sion.

TABLE V Determination of CMQ in Cycocel ${ }^{\circledR}$ and contaminated river water by the FIA proposed method, the corresponding recovery trials, and the relative error (RE)

\begin{tabular}{|c|c|c|c|c|}
\hline \multirow[t]{2}{*}{ Samples } & \multirow{2}{*}{$\begin{array}{l}\text { Nominalvalue } \\
(C M Q-C l)\end{array}$} & \multicolumn{2}{|l|}{ FIA } & \multirow[t]{2}{*}{$R E^{(\mathrm{a})}$} \\
\hline & & CMQ-Cl & Recovery & \\
\hline Cycocel $^{\oplus}$ & $400.0 \mathrm{~g} \mathrm{~L}^{-1}$ & $380.1 \pm 8.3(2.2 \%) \mathrm{g} \mathrm{L}^{-1}$ & $101.1 \pm 2.5 \%$ & $-4.8 \%$ \\
\hline River water & $160.0 \mathrm{mg} \mathrm{L}^{-1}$ & $168.1 \pm 7.4(4.4 \%) \mathrm{mg} \mathrm{L}^{-1}$ & $97.0 \pm 0.5 \%$ & p5.1\% \\
\hline
\end{tabular}

(a) estimated in terms of nominal value.

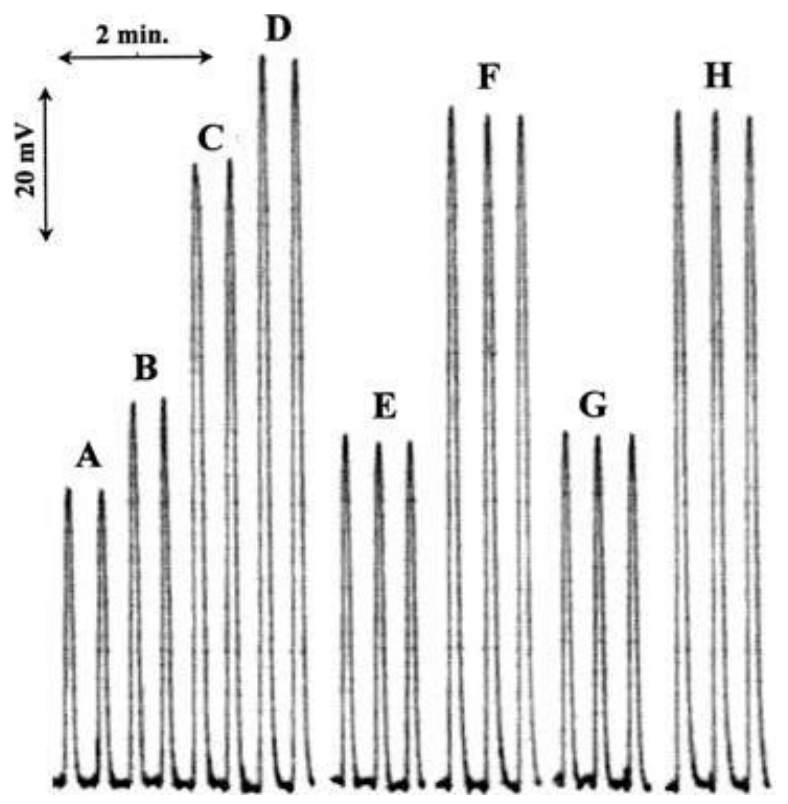

FIGURE 2 Fiagram for $C M Q$ standard solutions $(A-D)$, diluted Cycocel ${ }^{\circledR}(E, G)$, and the correspond-ing recovery trials $(\mathrm{F}, \mathrm{H})$. A: $5.0 \times 10^{-5} \mathrm{~mol} \mathrm{~L} \mathrm{~L}^{-1} ; \mathrm{B}: 1.0 \times 10^{-4} \mathrm{~mol} \mathrm{~L}^{-1} ; \mathrm{C}: 5.0 \times 10^{-4} \mathrm{~mol} \mathrm{~L}^{-1} ; \mathrm{D}: 1 \times 10^{-3}$ $\mathrm{mol} \mathrm{L} \mathrm{L}^{-1} ; \mathrm{E}, \mathrm{G}$ : estimated concentration of $7.7 \times 10^{-5} \mathrm{~mol} \mathrm{~L}{ }^{-1} ; \mathrm{F}, \mathrm{H}$ : estimated concentration of $7.0 \times 10^{-4}$ $\mathrm{mol} \mathrm{L}^{-1}$. 


\section{CONCLUSIONS}

The type C membrane presents a good alternative to other methods previously described in the literature, by CMQ determination in phytopharmaceuticals using potentiometric detection. The proposed system is simple, accurate and inexpensiveespecially regarding reagent consumption and equipment involved. It is therefore suit-able for routine procedures. The sample is prepared by making simple dilution withwater, therefore contributing to the preservation of both resources and quality ofenvironment. In terms of inorganic compounds, barium and phosphate generallycomprise the majority of the effluents produced at a $\mathrm{pH}$ of 6.3. For this reason, anadjustment of $\mathrm{pH}$ before discard is not required and the intensity of further pollutionfrom phosphate depends on the receptor; phosphate is of interest to agriculture. Thebarium may be isolated from solution by a simple precipitation reaction with anappropriate amount of sulphate. Taking into account the need for calibration and assuming 2 readings for each of four standard solutions, the FIA analysis of twosamples would produce about $40 \mathrm{~mL}$ of effluents. The intrinsic toxicity of the CMQis low, it is rapidly degraded in soil by microbiological activity and has no influence on soil microflora or fauna [31].

\section{Acknowledgements}

The authors thank Fundac, ão para a Cie^ncia e Tecnologia (FCT) for the financial support through projects POCTI/35287/AGR/2000 and POCTI/MGS/38801/2001 and Agroquisa for providing the commercial sample.

\section{References}

[1] W. Rademacher, Annu. Rev. Plant Physiol. Plant Molec. Biol., 51, 501-531 (2000).

[2] I.F. McKee and S.P. Long, New Phytol., 152, 41-51 (2001).

[3] R.Castro, E. Moyano and M.T. Galceran, J. AOAC Int., 84, 1903-1908 (2001).

[4] R. Castro, E. Moyano and M.T. Galceran, J. Chromatogr. A, 914, 111-121 (2001).

[5] C.S. Evans, J.R. Startin, D.M. Goodall and B.J. Keely, J. Chromatogr. A, 897, 399-404 (2000). [6] Y.

Pico, G. Font, J.C. Molto and J. Manes, J. Chromatogr. A, 882, 153-173 (2000).

[7] Y. Zhao, K. Lazou, M. Schelfaut, L. De Reu and P. Sandra, Chromatographia, 51, 531-535 (2000). [8]

H.G.J. Mol, R.C.J. Van Dam, R.J. Vreeken and O.M. Steijger, J. AOAC Int., 83, 742-747 (2000).

[9] J. Hau, S. Riediker, N. Varga and R.H. Stadler, J. Chromatogr. A, 878, 77-86 (2000).

[10] C.S. Evans, J.R. Startin, D.M. Goodall and B.J. Keely, Rapid Commun. Mass Spectrom., 14, 112-117 (2000).

[11] J.R. Startin, S.J. Hird, M.D. Sykes, J.C. Taylor and A.R.C. Hill, Analyst, 124, 1011-1015 (1999). [12]

M. Vahl, A. Graven and R.K. Juhler, Fresenius J. Anal. Chem., 361, 817-820 (1998).

[13] D. Barcelo, G. Durand and R.J. Vreeken, J. Chromatogr., 647, 271-277 (1993).

[14] J. Horak, W. Werther and E.R. Schmid, Rapid Commun. Mass Spectrom., 15, 241-248 (2001).

[15] D. Wycherley, M.E. Rose, K. Giles, T.M. Hutton and D.A. Rimmer, J. Chromatogr. A, 734, 339-349 (1996).

[16] E. Moyano, D.E. Games and M.T. Galceran, Rapid Commun. Mass Spectrom., 10, 1379-1385 (1996). [17]

J.P. Lautie, V. Stankovic and G. Sinoquet, Analusis, 28, 155-158 (2000).

[18] M.C. Peeters, I. Defloor, J. Coosemans, J.A. Delcour, L. Ooms, R. Deliever and D. De Vos, J. Chromatogr. A, 920, 255-259 (2001).

[19] M.T. Galceran, M.C. Carneiro, M. Diez and L. Puignou, J. Chromatogr. A, 782, 289-295 (1997).

[20] R.P. Mooney and N.R. Pasarela, J. Agric. Food Chem., 15, 989-993 (1967).

[21] W.J. Allender, Pestic. Sci., 35, 265-269 (1992).

[22] R.D. Mortimer and D.F. Weber, Pestic. Sci., 40, 31-35 (1994).

[23] P. Bianco and N. Aghroud, Electroanalysis, 9, 602-607 (1997). 
[24] J. Kolecek, V. Riha and K. Vytras, Anal. Chim. Acta, 273, 431-433 (1993).

[25] S. Alegret, J. Alonso, J. Bartroli, J.M. Paulis, J.L.F.C. Lima and A.A.S.C. Machado, Anal. Chim. Acta, 164, 147-152 (1984).

[26] S. Alegret, J. Alonso, J. Bartroli, A.A.S.C. Machado, J.L.F.C. Lima and J.M. Paulis, Quim. Anal., 6, 278-294 (1987).

[27] R.P. Buck and E. Lindner, Pure appl. Chem., 66, 2527-2536 (1994).

[28] T. Okada, H. Sugihara and K. Hiratani, Analyst, 120, 2381-2386 (1995).

[29] R.D. Amstrong, H. Wang and M. Todd, J. Electroanal. Chem., 266, 173-174 (1989).

[30] W. Dobrat, Chlormequat-chloride Technical Concentrate, CIPAC 143/TK/M2/-ion Chromatographic Method, German Committee (DAPA), Germany (1997).

[31] C.D.S. Tomlin (Ed.), The Pesticide Manual (British Crop Protection Council, 1998), 11th edn, pp. 220-222. 